Canadian Journal of Microbiology

Canadian

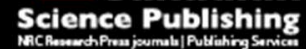
Revue canadienne de de microbiologie

Frogs host faecal bacteria typically associated with humans

\begin{tabular}{|r|l|}
\hline Journal: & Canadian Journal of Microbiology \\
\hline Manuscript ID & cjm-2017-0119.R1 \\
\hline Manuscript Type: & Article \\
\hline Date Submitted by the Author: & $11-$ Apr-2017 \\
\hline Complete List of Authors: & $\begin{array}{l}\text { Gibb, Karen; Charles Darwin University, School of Environment } \\
\text { Schobben, Xavier; Northern Territory Department of Health and Families, } \\
\text { Environmental Health Branch } \\
\text { Christian, Keith; Charles Darwin University, School of Environment }\end{array}$ \\
\hline Keyword: & Drinking water, Sewage, Water quality, Frogs \\
\hline &
\end{tabular}




\title{
Frogs host faecal bacteria typically associated with
}

\author{
humans
}

Karen Gibb', Xavier Schobben² \& Keith Christian'

'Research Institute for the Environment and Livelihoods, Charles

Darwin University, Darwin, Northern Territory 0909, Australia;

karen.gibb@cdu.edu.au; keith.christian@cdu.edu.au;

2Environmental Health Branch, Department of Health, PO Box

40596, Casuarina, Northern Territory 0810, Australia;

Xavier.Schobben@nt.gov.au 


\section{Correspondence}

Keith Christian, Research Institute for the Environment and

Livelihoods, Charles Darwin University, Darwin, Northern Territory

0909, Australia. Email: keith.christian@cdu.edu.au 


\section{Abstract}

Tree frogs commonly access drinking water tanks, which may have human health implications. Although amphibians might not be expected to host mammalian faecal indicator bacteria (FIB), it is possible that they may have human FIB on their skin after exposure to human waste. We collected faeces and skin wash from green tree frogs (Litoria caerulea) from a natural environment, a suburban site, and a suburban site near a creek occasionally contaminated with sewage effluent. We used molecular techniques to test for FIB that are routinely used to indicate human faecal contamination. Enterococci colonies were isolated from both faecal and skin wash samples, and specific markers (E. faecium and B. thetaiotamicron) were found in frog faeces, demonstrating that these markers are not human or mammalianspecific. B. thetaiotamicron was detected in frogs from both natural and urban sites, but E. faecium was only associated with the sewage impacted site.

\section{Key words}

Animals; drinking water; sewage; water quality. 


\section{Introduction}

The safety of drinking water is a fundamental public health issue, particularly in the tropics where high temperatures are conducive to bacterial growth. One of the standard tests for water quality is to measure levels of enterococci because they are considered to be reliable mammalian-specific faecal indicators (National Health and Medical Research Council 2008). Tests for E. faecium are considered to be more specific for human faeces than the genus level test (Scott et al. 2005), however dogs and seals have also been shown to be positive for this species (Layton et al. 2009). The public health implication of detecting E. faecium in non-human hosts is not well understood, and one solution has been to advocate multiple tests that target a range of microbes generally associated with human faeces (Neave et al. 2014). As a result, we now have more targets for human FIB tests including Bacteroides thetaiotamicron that is widely thought to be human-specific (Teng et al. 2004). The predominance of $B$. thetaiotaomicron in human feces makes it a worthy candidate as a marker of human fecal matter. Although these targets are not necessarily human specific, it has been assumed that they are 
mammalian specific. Since the health risk for contact with human feces is generally higher than that with non-human feces, this is an important development in terms of identifying human fecal matter (Carson et al. 2005).

Our interest in non-mammalian hosts was sparked by an anecdotal report that residents of a remote community in the wet-dry tropics of northern Australia were experiencing symptoms of gastroenteritis and a link was made to the quality of water in domestic rainwater tanks. Green tree frogs (Litoria caerulea) commonly inhabit these water tanks in northern tropical Australia, leading us to investigate whether in fact these frogs can host bacteria typically associated with human faeces. L. caerulea is an important source of yeasts in water storage reservoirs in areas where the animal is endemic (Sammon et al., 2009; 2010), so if frogs do host faecal bacteria that are commonly thought to be human-specific, this has further implications for human health.

If these bacteria were present, we also wanted to determine whether the bacteria were in frog faeces, on their skin, or both. If frogs carry these bacteria on their skin, they might contaminate drinking water for human consumption even without defecating in the water supply. Furthermore, if 
frogs are hosts for indicator bacteria, we wanted to determine if this occurs in natural habitats, or whether it is only found in close association with humans. If the frogs are contaminated from humans, does this result from routine exposure (typical suburban associations, including possible contact with toilets), or is it a result of direct exposure to sewage outflows? To answer these questions, we collected faeces and skin wash from Litoria caerulea from a suburban area (suburban), a suburban area next to a creek that is known to sometimes receive sewage effluent (contaminated), and a natural (reference) environment. We then used molecular techniques to test for the presence of bacteria that are routinely used to detect human faecal contamination Enterococcus faecium and Bacteroides thetaiotamicron.

\section{Materials and methods}

\section{Sites}

Green tree frogs were sampled from three sites in the vicinity of Darwin, Northern Territory, Australia. The suburb of Ludmilla is an area in which frogs inhabit suburban gardens adjacent to Ludmilla Creek, which receives periodic 
sewage discharges (referred to as potentially "contaminated") (Hind, 2014).

The suburb of Brinkin represents an area in which frogs inhabit suburban gardens that are not near sewage outlets (referred to as "suburban"). The area near Mickett Creek (MC) on the outskirts of Darwin represents a natural or "reference" site of approximately 50 ha with natural vegetation typical of wet-dry tropical savannah habitat. Here, the frogs live in trees instead of being associated with buildings.

\section{Frogs}

Ten green tree frogs (Litoria caerulea) were captured by hand (using fresh, disposable gloves) from both Ludmilla Creek and Brinkin, but despite multiple trips and intense searching we were only able to find and capture three frogs at Mickett Creek. Soil samples from near each capture location were also collected. Once the frogs were brought into the lab, skin wash was collected as follows.

One researcher slowly poured $50 \mathrm{~mL}$ of sterile distilled water over the frog as another researcher held the frog and gently massaged its skin. This washing is hereafter referred to as skin wash (SW). Each frog was then placed in a ventilated plastic container, and placed in a constant temperature room at $30^{\circ} \mathrm{C}$. The plastic containers were tilted so that the frogs had access to water 
at one end, but the other end was dry. The frogs were checked every few hours, and faecal samples were removed from the containers as soon as they were found. Once a frog defecated, it was released at night at its original capture location.

\section{Enterococci enrichment}

Faeces were collected and suspended in sterile phosphate buffered saline (PBS) at a ratio of $1: 10$, shaken for $10 \mathrm{~min}$ at room temperature and allowed to settle. A $200 \mu \mathrm{L}$ sample of the faecal suspension was plated onto enterococci-specific mEl Agar overlaid with a sterile, white, gridded $47 \mathrm{~mm}$ diameter, $0.45 \mu \mathrm{m}$ pore size membrane filter, and plates were then processed according to standard methods (USEPA 2006). SW was collected as described above, and $25 \mathrm{~mL}$ samples were filtered under suction through a membrane filter and enriched for enterococci as described for faeces. A $10 \mathrm{~g}$ aliquot of each soil sample was mixed with $60 \mathrm{~mL}$ PBS, shaken by hand for $2 \mathrm{~min}$ and allowed to settle for $30 \mathrm{~s}$. This eluant was decanted into another bottle and $40 \mathrm{~mL}$ PBS was added to the original $10 \mathrm{~g}$ of soil, shaken and settled. The two eluants were mixed and filtered under suction through a membrane filter. The filter was transferred to $\mathrm{mEl}$ media and enriched for enterococci as described for faeces. 


\section{Enterococci DNA extraction}

After incubation of faeces, SW and soil plates, colonies approximately $0.5 \mathrm{~mm}$ in diameter with a blue halo were transferred to $4 \mathrm{~mL}$ Tryptic Soy Broth (TSB), vortexed and incubated at $41^{\circ} \mathrm{C}$ for $3 \mathrm{~h}$ in a shaker. The TSB and filter was then centrifuged for 5 min @ $4500 \mathrm{~g}$. DNA was extracted from the resulting pellet using the MoBio Microbe ${ }^{\bullet}$ DNA extraction kit according to the manufacturer's instructions. The purified DNA was taken up in $100 \mu \mathrm{L}$ of sterile $10 \mathrm{mM}$ Tris and stored DNA frozen at $-20^{\circ} \mathrm{C}$.

\section{Total DNA extraction from SW}

DNA was extracted from $0.25 \mathrm{~g}$ of faeces using the MoBio PowerSoil ${ }^{\circ}$ DNA Isolation Kit. For SW, $25 \mathrm{~mL}$ was filtered as described above, and DNA was extracted from the filter using the PowerWater ${ }^{\circledR}$ DNA Isolation Kit. DNA was extracted from the $10 \mathrm{~g}$ soil sample using the MoBio PowerMax ${ }^{\circledR}$ Soil DNA Isolation Kit. All extraction and filtering processes were undertaken in accordance with the manufacturers' instructions.

DNA test for 'human' faecal markers Enterococcus faecium and Bacteroides thetaiotamicron 
A $680 \mathrm{bp}$ fragment of the E. faecium esp gene and $542 \mathrm{bp}$ fragment of the $B$. thetaiotamicron 16SrRNA gene were amplified by the polymerase chain reaction (PCR) using the $\mathrm{MyTaq}^{\oplus} \mathrm{PCR}$ mix (Bioline, USA) in $50 \mu \mathrm{L}$ volumes (Neave et al. 2014).

\section{Statistical Comparisons}

The Fisher Exact Probability Test was used in pair-wise comparisons between sites to determine differences in occurrence of the bacteria in faeces, soil and skin wash. 


\section{Results}

Enterococci colonies grew in most faecal and soil plates regardless of location, but only grew in two skin wash samples, specifically from the suburban location (Fig. 1). The E. faecium test, using the plated enterococci DNA as template, was negative for all skin wash and soil samples. However, the $E$. faecium test was positive for some faecal samples, but only from the sewage-impacted site (Fig. 1), with the occurrence being significantly higher $(p=0.04)$ in this site compared to the suburban site.

The human faecal marker B. thetaiotamicron was detected in faecal DNA samples from all locations, but not in skin wash or soil samples (Fig. 1). The occurrence of $B$. thetaiotamicron was not significantly different among the three sites, including the reference site ( $p$-values ranging between $0.07-$ $0.56)$. 


\section{Discussion}

The results of this study identified that the standard genus level test, using enterococci-specific media, detected enterococci in amphibian faeces. Sammon et al. (2009 and 2010) also reported that frog faeces were positive for E. coli, the other common faecal indicator bacteria. Our results indicate that there is reason to doubt the reliability of using either enterococci or $E$. coli as tests for mammalian faecal indicator bacteria. We also tested for B. thetaiotaomicron because it is considered to be an effective indicator of human faeces (Carson et al. 2005) and found that frog faecal DNA is positive for this bacteria. Given that both of the 'human' faecal indicator tests (E. faecium and B. thetaiotamicron) were positive in tree frog faeces, this adds to the growing evidence that currently used indicator bacteria are not as specific as initially believed (Layton et al. 2009; Radimersky et al. 2010). Although we cannot definitively state that the small sample of reference frogs had never been exposed to human sewage, it seems unlikely because they were found using natural tree hollows several kilometers from any buildings. Therefore, when questions specifically relate to human faecal contamination, results from currently used markers must be interpreted with caution. 
However, these bacteria are nevertheless useful indicators of faeces, and for drinking water this would be a concern even if derived from an animal host because these bacteria occur in human faeces and may pose a potential public health risk. Our results show that frogs congregating in water tanks and defecating into the water could contaminate that water with these bacteria - and presumably other bacteria such as member of the Firmicutes commonly found in human faeces (Walker et al. 2011). Where there is no evidence of frog defecation, it is considered that these frogs do not pose the same type of health risk because there was no evidence that they can 'vector' these bacteria on their skin. Importantly, B. thetaiotamicron was detected in frog faeces regardless of the presence of a source such as sewage effluent. These results indicate that frogs become hosts to faecal bacteria (that are commonly thought to be humanspecific) whether they live in close contact with humans (i.e. suburban frogs) or in the natural environment. In contrast, E. faecium was only detected in frog faeces at the sewage-impacted site. This suggests the possibility that frogs become hosts to E. faecium only when they live in suburban areas contaminated with sewage effluent. However, a larger sample would need to be tested to confirm that pattern. 
With respect to our original aims, we determined that frogs can host bacteria typically associated with human faeces, and although Enterococci colonies were present in both faecal and skin wash samples, the more specific markers (E. faecium and B. thetaiotamicron) were only found in faeces. With respect to our aim related to the source of the bacterial markers, faecal $B$.

thetaiotamicron was detected from populations of frogs from both natural and urban sites, but E. faecium was only associated with the sewage impacted urban site. Both E. faecium and B. thetaiotamicron have been isolated from faeces collected from humans with symptoms of gastroenteritis (Ke et al. 1999; Kong et al. 2002; Teng et al. 2004). While more research would need to be done in this tropical context, the potential exists for people drinking water that contains frog faeces, to ingest bacteria that could replicate in their gut and cause illness. Moreover, other workers have shown that frogs contained E. faecium with antibiotic resistance conferred by a transposable element or 'jumping gene'. If these bacteria can be shed in drinking water, there is potential for their dissemination and uptake by humans (Rana et al. 2011).

Our recommendation therefore is that water tanks used to store drinking water should be properly constructed, sealed and maintained to guard against frogs. Our results are likely to be included in an update of the Commonwealth 
of Australia Department of Health Guidance on use of rainwater tanks (2011), particularly the sections on microbiology testing and faecal contamination from small animals, with a specific recommendation about frogs.

\section{Conclusions}

(1) The human faecal indicator bacteria tested in this study were found in association with tree frog faeces, casting doubt on the validity of them being considered human or mammalian specific.

(2) Bacteroides thetaiotamicron was found in frogs faeces from all sites, including the natural site where the frogs lived in trees rather than being associated with human structures.

(3) Enterococcus faecium was only found in frog faeces from the suburban site near a creek that sometimes receives sewage effluent.

(4) Although we have not established a link between tree frogs and human health issues, these results suggest that it would be prudent to ensure drinking water tanks are constructed and sealed in such a manner to exclude entry by frogs.

\section{Acknowledgements}


We thank the Northern Territory Department Health for funding assistance in this project, and Deborah-Ann Gillon and Jake Christian for assistance in the laboratory and the field. Frogs were collected under permit \#A12003 from the Charles Darwin University Animal Ethics Committee and permit \#43962 from the Northern Territory Parks and Wildlife Commission.

\section{References}

Carson, C.A., Christiansen, J.M., Yampara-Iquise, H., Benson, V.W., Baffaut, C., Davis, J.V., Broz, R.R., Kurtz, W.B., Rogers, W.M. and Fales, W.H. 2005. Specificity of a Bacteroides thetaiotaomicron marker for human feces. Appl. Environ. Microbiol. 71(8): 4945-4959.

Commonwealth of Australia Department of Health. (2011) Guidance on Use of Rainwater Tanks.

http://www.health.gov.au/internet/publications/publishing.nsf/Content/ohp -enhealth-raintank-cnt-I [accessed 5 February 2016].

Hind, R. (2014) Sewage from treatment plant spills into Ludmilla Creek in Darwin [online]. Available at http://www.abc.net.au/news/2014-08-

\section{9/darwin-wastewater-treatment-plant-spills-266000-litres/5681564}

[accessed 5 February 2016]. 
Ke, D., Picard, F.J., Martineau, F., Ménard, C., Roy, P.D., Ouellette, M. and Bergeron, M.G. 1999. Development of a PCR assay for rapid detection of enterococci. J. Clin. Microbiol. 37(1 1): 3497-3503.

Kong, R.Y.C., Lee, S.K.Y., Law, T.W.F., Law, S.H.W. and Law, R.S.S. 2002. Rapid detection of six types of bacterial pathogens in marine waters by multiplex PCR. Water Res. 36(11): 2802-2812.

Layton, B.A., Walters, S.P. and Boehm, A.B. 2009. Distribution and diversity of the enterococcal surface protein ( $e s p)$ gene in animal hosts and the Pacific coast environment. J. Appl. Microbiol. 106(5): 1521-1531.

National Health and Medical Research Council. 2008. Guidelines for managing risks in recreational water. Australian Government: Canberra, Australia.

Neave, M., Luter, H., Padovan, A., Townsend, S., Schobben, X. and Gibb, K. (2014) Multiple approaches to microbial source tracking in tropical northern Australia. MicrobiologyOpen 3(6): 860-874.

Radimersky, T., Frolkova, P., Janoszowska, D., Dolejska, M., Svec, P., Roubalova, E., Cikova, P., Cizek, A. and Literak, I. 2010. Antibiotic resistance in faecal bacteria (Escherichia coli, Enterococcus spp.) in feral pigeons. J. Appl. Microbiol. 109(5): 1687-1695. 
Rana, S.W., Kumar, A., Walia, S.K., Berven, K., Cumper, K. and Walia, S.K.

2011. Isolation of $\operatorname{Tn} 1546$-like elements in vancomycin-resistant

Enterococcus faecium isolated from wood frogs: an emerging risk for

zoonotic bacterial infections to humans. J. Appl. Microbiol. 110(1): 35-43.

Sammon, N.B., Harrower, K.M., Fabbro, L.D. and Reed, R.H. 2009. Green tree

frogs: Contamination of covered reservoirs in Northern Australia. Water 36(4):

97-101.

Sammon, N.B., Harrower, K.M., Fabbro, L.D., and Reed, R. H. 2010. Microfungi

in drinking water: The role of the frog Litoria caerulea. Int. J. Environ. Res.

Public Health $\pi 8$ ): 3225-3234.

Scott, T.M., Jenkins, T.M., Lukasik, J. and Rose, J.B. 2005. Potential use of a host associated molecular marker in Enterococcus faecium as an index of human fecal pollution. Environ. Sci. Technol. 39(1): 283-287.

Teng, L.J., Hsueh, P.R., Huang, Y.H. and Tsai, J.C. 2004. Identification of Bacteroides thetaiotaomicron on the basis of an unexpected specific amplicon of universal 16S ribosomal DNA PCR. J. Clin. Microbiol. 42(4): 1727-2730. 
USEPA. (2006) Method 1600: Enterococci in Water by Membrane

Filtration Using membrane-Enterococcus Indoxyl- $\beta$-D-Glucoside Agar (mEl) July 2006. EPA-821-R-06-009.

Walker, A.W., Ince, J., Duncan, S.H., Webster, L.M., Holtrop, G., Ze, X., Brown, D., Stares, M.D., Scott, P., Bergerat, A., Louis, P., Mclntosh, F., Johnstone, A.M., Lobley, E., Parkhill, J. and Flint, H.J. 2011 . Dominant and diet-responsive groups of bacteria within the human colonic microbiota. ISME J. 5(2): 220230. 
Fig. 1. The percentage of samples that were positive for Enterococci colonies, E. faecium, or B. thetaiotamicron from tree frog faeces, skin wash, and soil samples collected at three sites i.e. a natural reference, suburban, and contaminated (sewage impacted). 


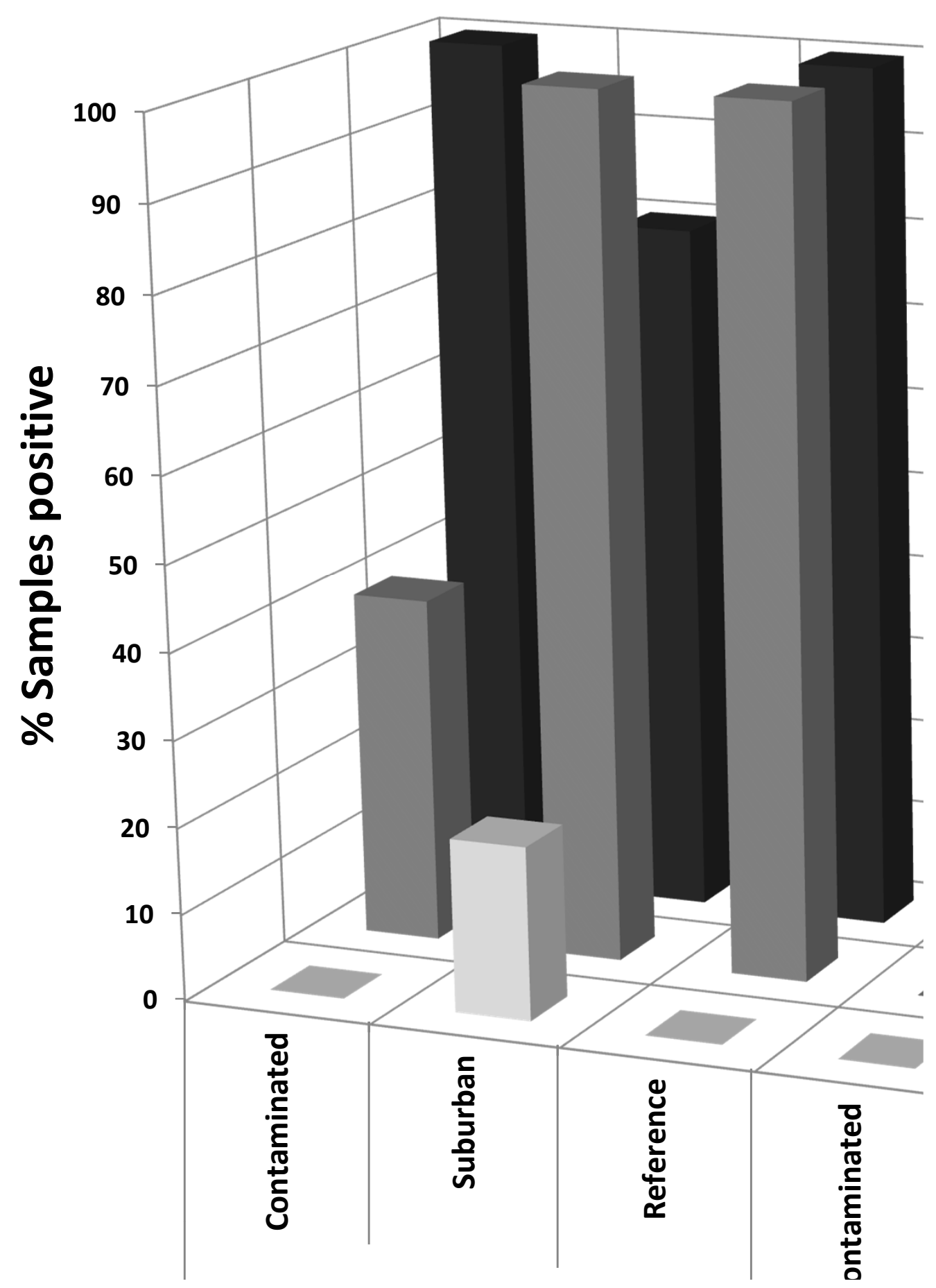




\section{Enteroccus colonies}




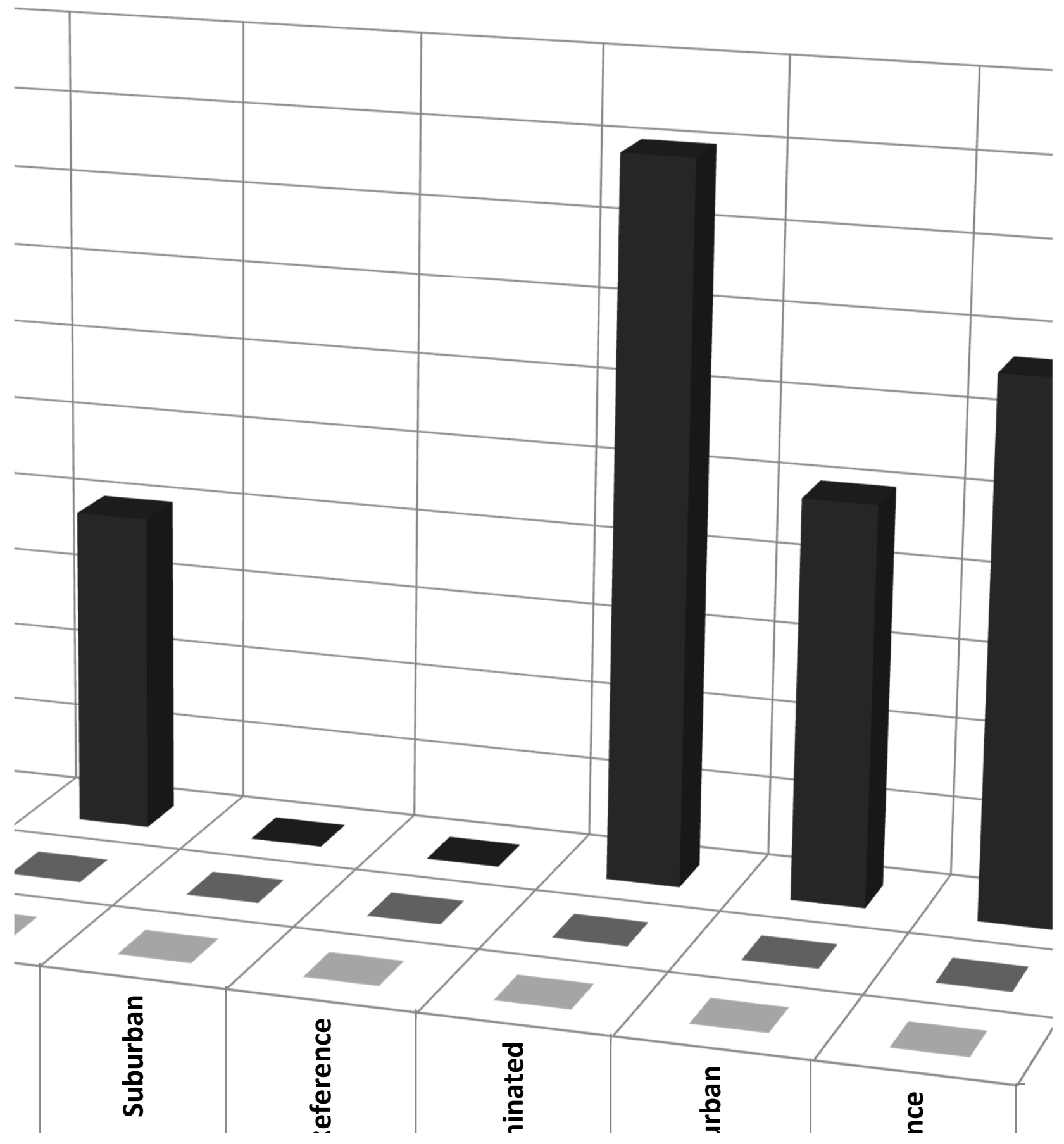


$\propto$

\section{E. faecium}

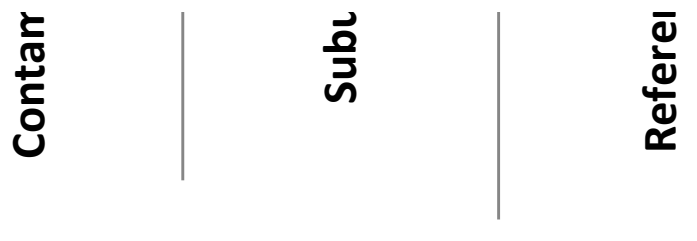

Bacteroides thetaiotamicron 


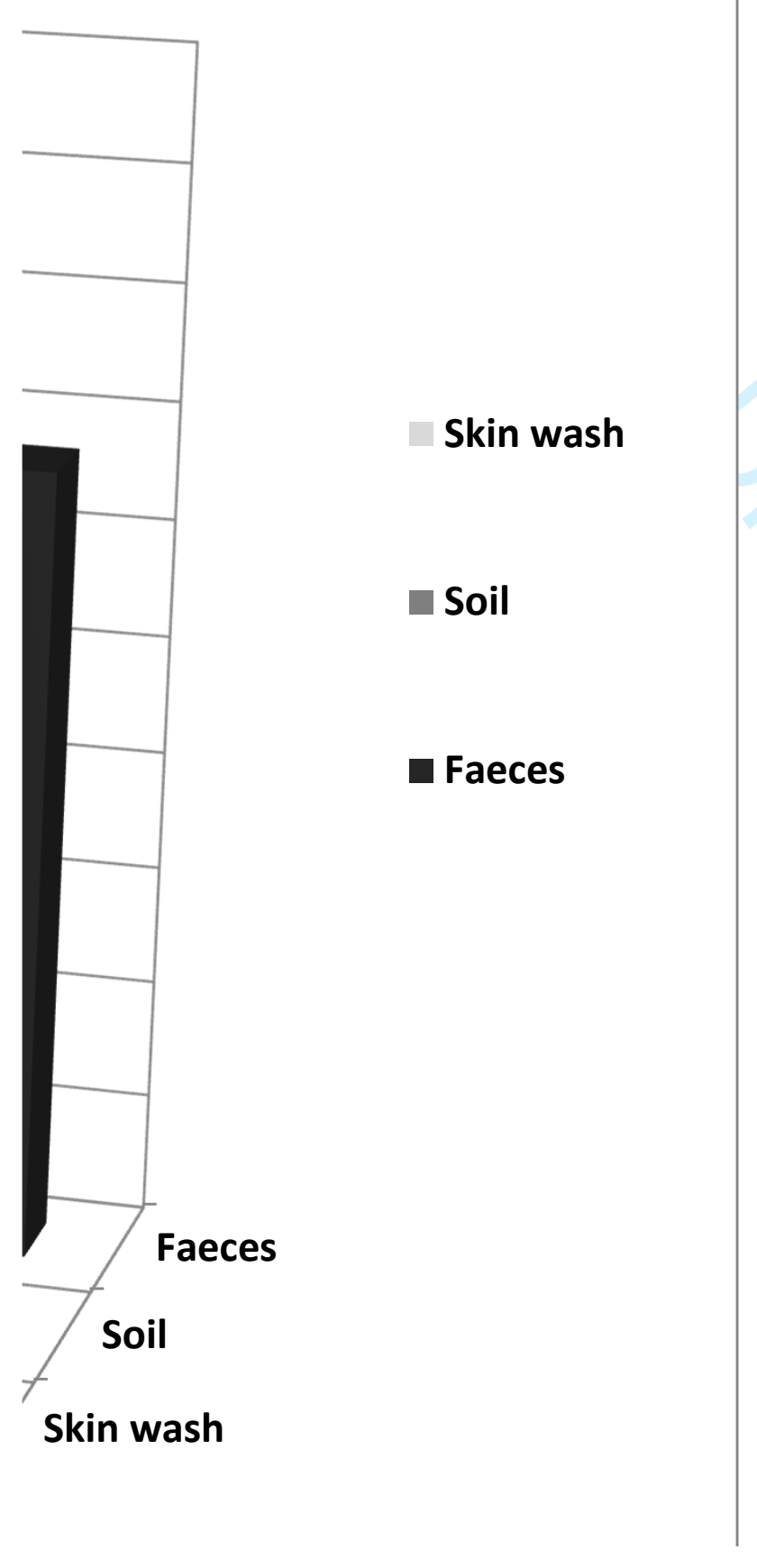


